\title{
EARLY PUERPERAL COMPLICATIONS - A PROSPECTIVE CLINICAL STUDY ON CAESAREAN DELIVERIES
}

\author{
AKHTER T ${ }^{1}$, GHANI T ${ }^{2}$, PAUL $\mathrm{SK}^{3}$, NOORJAHAN ${ }^{4}$, BEGUM A ${ }^{5}$, RAHMAN $\mathrm{T}^{6}$, SARKAR $\mathrm{M}^{7}$
}

\begin{abstract}
:
Introduction: when a healthy pregnant woman with no obstetric or medical risk factors goes into spontaneous labour, she should anticipate a normal delivery. But still 580, 000 women in the world die from pregnancy and childbirth each year. ${ }^{1}$ Lack of attention to postpartum care in developing countries is neglected tragedy and requires immediate attention. This study evaluates the incidence of complications of early puerperium and also focuses the specific types of complications and to detect the risk factors associated with these complications.
\end{abstract}

Aims and objectives : Main aim of the study is to evaluate the common complications in early puerperium with special attention to identify the risk factors.

Materials and method: This study was carried out in Dhaka Medical College Hospital and Sir Sallimullah Medical College Hospital within the period of March '2004 to August' 2004. Two hundred patients were selected for this study who were delivered by caesarean section in these two institutions and complications occurring within 7 days excluding first 24 hours. Patients delivered outside the hospital and with known medical diseases were excluded from this study. Detailed history taking and appropriate clinical examination and specific investigations were done for diagnosis of complications. All relevant informations was noted in prescribed data sheet and results were tabulated and statistical analysis was done.

Results : Among 200 cases only 44(22\%) cases had early puerperal morbidity. Most of the patients who suffered complications underwent caesarean section for obstructed labour and fetal distress who had trial at home. Many of the patients suffered from wound infection and endometritis (40.9\%). Among patients, age group $-<20$ years suffered from wound infection(53.8\%) and endometritis(45.8\%) were common in age group 21-30 years. VVF was common in patients in age $<20$ years. Endometritis (42.2\%) was maximum in women with parity $1-3$ and wound infection (50\%) in women with parity 4-6. Some of the patients had more than one early puerperal morbidity. Maximum number of poor class suffered from wound infection (42.4\%). Early puerperal morbidity was more prevalent in women with duration of labour $<18$ hours and Premature rupture of membrane had relationship with endometritis (15.9\%), wound infection (13.6\%) and UTI (11.4\%).

Conclusion : Incidence of early puerperal morbidities is still quite high (22\%) and many patients experiences more than one problem at a time.Long term sequelae of early puerperal infectious morbidity should not be neglected as this may interfere quality of life of a woman.

Key words : Puerperium, PROM (Premature rupture of membrane).

J Dhaka Med Coll. 2018; 27(1) : 68-71

\section{Introduction:}

Puerperium is the period of adjustment after delivery when the anatomic and physiologic changes of pregnancy are reversed and body returns to the normal non-pregnant state. ${ }^{2}$ Puerperium begins as soon as the placenta is expelled and lasts for 6 weeks and early puerperal period extends until first week of postpartum. ${ }^{3}$ Puerperium is a time of great importance for both the mother and baby and yet it is an aspect of maternity care that has received relatively less attention than pregnancy

1. Dr. Tahamina Akhter, Assistant Professor (Gynae), Dhaka Medical College, Dhaka.

2. Dr.Tabassum Ghani, Associate Professor (Gynae), Dhaka medical college, Dhaka.

3. Dr. Subinoy Krishna Paul, Associate Professor (Surgery), Dhaka medical college, Dhaka.

4. Dr. Noorjahan, Assistant Professor (Gynae), Dhaka Medical College, Dhaka.

5. Dr. Afrina Begum, Associate Professor (Gynae), Dhaka Medical College, Dhaka.

6. Dr. Tashrifa Rahman, Medical Officer, Upazilla Health Complex, Bakerganj, Barisal.

7. Dr. Mandira Sarkar, Junior Consultant (Gynae), Upazilla Health Complex, Shibpur, Nrasingdi.

Address of Correspondence : Dr. Tahamina Akhter, Assistant Professor (Gynae), Dhaka Medical College, Dhaka. Phone-01715088813. Email - lovelyakhter13@gmail.com

Received: 21 July $2017 \quad$ Revision: 01 September 2017

Accepted: 25 October 2017 
and delivery. ${ }^{4}$ During early puerperal period a woman can suffer a number of complications particularly after an operative delivery. Common problems in early puerperium are puerperal pyrexia due to puerperal sepsis, UTI, wound infection, respiratory infection, thrombophlebitis or thromboembolism, breast complications (mastitis) and other complications like secondary postpartum haemorrhage, cardiomyopathy, seizures, depression, bowel and bladder dysfunction, VVF etc. Maternal mortality in developing countries is 100 times higher than developed countries. ${ }^{1}$ Much attention has been focused on prenatal care for preventing maternal mortality but very few studies have examined postpartum care, even though over half of all maternal death occur in postpartum period. ${ }^{5}$ This study examines the incidence of complications of early puerperium by evaluating cases and also focuses specific types of complications and to detect the risk factors associated with the complications of early puerperium.

\section{Aims and objectives:}

Main aim of the study is to evaluate the common complications in early puerperium with special attention to identify the risk factors to minimize morbidity as well as mortality. Specific objectives to find out incidence, types and risk factors associated with complications in early postpartum period.

\section{Methodology :}

This study was conducted in Dhaka Medical College Hospital and Sir Sallimullah Medical College and Mitford Hospital which are tertiary referral hospitals situated in the capital city Dhaka within a period of March'2004 to August'2004. Many patients come in these institutions particularly with complications. Caesarean section is done whenever there are definite indications. Two hundred cases were randomly selected for this study who were delivered by caesarean section and complications occurring within 7 days excluding first 24 hours. Detailed history was taken with special attention to risk factors developing puerperal morbidity like duration of labour, duration of rupture membrane, prophylactic antibiotic, trial at home, fever, foul smelling discharge. Breast complications like engorgement, cracked nipple, mastitis, thrombophlebitis were looked for. Urine, high vaginal swab, wound swab were sent for culture sensitivity. Patients with known medical diseases and patients delivered outside the hospital were excluded from this study. All the relevant informations were noted in a prescribed data sheet and results were tabulated and statistical analysis was done.

\section{Results :}

A total number of 200 patients were included in this study, out of which $44(22 \%)$ cases had early puerperal morbidity. They are divided into two groups- Group A women with postoperative complications and Group B without complications. Mean age of the patients were $25.06 \pm 5.65$ years in Group A and 24.804 .53 years in Group B (P= 0.202, Not Significant). In group A, 40(90.9\%) women and group B, 146 $(93.6 \%)$ were in parity $1-3$ and $4(9.1 \%)$ vs $10(6.4 \%)$ women were in parity 4-6 Group A and $B$ respectively $(P=0.538$, Not significant). Maximum number of women in both group A and group B were housewives (93.2\% vs $91.7 \%)$ and rest were service holders (6.8\% vs $8.3 \%)$ $(\mathrm{P}=0.744$, not significant). Most of the women were on irregular antenatal care $(72 \%)$, only $6(3 \%)$ had regular antenatal care. In this study, maximum number of women of both groups were mildly anaemic ( $84.1 \%$ vs $87.8 \%)$ and with moderate anaemia $(15.9 \%$ vs $11.5 \%)(\mathrm{P}=0.650$, not significant).

In Group A, Indications of caesarean section and type of post caesarean early puerperal morbidity were shown in Table I and II respectively.

\section{Table I}

Indications of caesarean section in patients with early puerperal morbidity $(n=44)$

\begin{tabular}{lcc}
\hline Indications & No. of patients & Percentage \\
\hline Obstructed labour & 10 & 22.7 \\
Fetal distress & 8 & 18.2 \\
PROM with & 7 & 15.9 \\
chorioamnionitis & & \\
PROM & 6 & 13.6 \\
PIH & 4 & 9.1 \\
History of previous c/s & 3 & 6.8 \\
Malpresentation & 3 & 6.8 \\
APH & 2 & 4.5 \\
Heart disease & 1 & 2.3 \\
\hline
\end{tabular}


Table II

Types of post caesarean early puerperal morbidity $(n=44)$

\begin{tabular}{lcc}
\hline Morbidity & No. of patients & Percentage \\
\hline $\begin{array}{l}\text { Infectious morbidity } \\
\text { Wound infection }\end{array}$ & 18 & 40.9 \\
Endometritis & 18 & 40.9 \\
UTI & 15 & 34.1 \\
Mastitis & 2 & 4.5 \\
OthersVVF & 2 & 4.5 \\
Obstetric Palsy & 1 & 2.3 \\
Heart failure & 1 & 2.3 \\
Postpartum blue & 1 & 2.3 \\
\hline
\end{tabular}

Many of the patients had more than one morbidity at a time i.e. patients who had endometritis had concomitant UTI. Many patients who had caesarean section for obstructed labour had endometritis and only 2 developed VVF. In this study, many of the patients suffered from wound infection and endometritis. Duration of labour was $<18$ hours in $13(29.5 \%)$ cases and $>18$ hours in $31(70.5 \%)$ cases. Mean duration of labour were 9.686 .73 hours (range $0-18$ hours) and 24.383 .55 hours (range 20-30 hours respectively). Large percentage of patients age group $<20$ years suffered from wound infection (53.8\%), while endometritis was common among patients belonging to age group 21-30 years (45.8\%). VVF was common in patients in the age group $<20$ years $(15.4 \%)$ (i.e. younger age group). Endometritis (42.2\%) was maximum in women with parity 4-6. Some of the patients had more than one early puerperal morbidity. Poor class suffered from wound infection $14(42.9 \%)$, Endometritis 13(39.4\%), 12(36.4\%), VVF $2(6.1 \%)$ and heart failure $1(3 \%)$ case. Relationship of PROM with early puerperal morbidity stated that $7(15.9 \%)$ had endometritis, $6(13.6 \%)$ cases had wound infection and $5(11.4 \%)$ cases had UTI. There were no other morbidity in patients with PROM.

\section{Discussion :}

This study showed overall incidence of early puerperal morbidity was $22 \%$, this value is quite high in comparison to studies of developed countries where incidence has been found to 5.5 in one study. ${ }^{6}$ Age distribution of the patients were 21-30 years and and para 1-3 with low socioeconomic status. Mostly were housewife and had no or irregular antenatal check up. These observation almost consistent with the findings of Rowshan A who worked on patients of early puerperium in Mymensingh medical college. ${ }^{7}$ Common indications of caesarean section with early puerperal morbidity were obstructed labour and fetal distress in this study but in a study conducted by Deeba F in Rajshahi medical college hospital on patients undergoing caesarean section showed that foetal distress (19.75\%) and prolonged labour (17.69\%) were two common indications. ${ }^{8}$ Puerperal sepsis was second most common cause of maternal morbidity in developing world ${ }^{9}$ but now there had been a dramatic decline in the prevalence due to prophylactic antibiotics. In the present study the incidence of wound infection and endometritis had $40.9 \%$, this is high in comparison to many studies of developed world where only $2-8 \% .{ }^{7}$ Risk factors for early puerperal morbidities were belonged to 21-30 years, para 1-3, coming from low socioeconomic status, had labour $>18$ hours, presented with PROM. This observation is almost similar to many other studies. ${ }^{1011} 12131415$ In another study by Rehu $\mathrm{M}$ et $\mathrm{al}^{11}$ found incidence of post caesarean febrile morbidity was $20.5 \%$ among it endometritis $9.8 \%$, UTI $7.3 \%$ and wound infection $6.8 \%$. The risk factors were almost similar to our present study. UTI is a common puerperal infection as catheterization is almost always done during caesarean section. Garber $B$ et al showed that UTI was significantly more frequent in women subjected to catheterization $(54.5 \%)$ compared to non- catheterization (24.4\%). ${ }^{16}$ The incidence of puerperal mastitis was low ( 1 in 44 ) in this study which may be due to the fact that our patients are well motivated and culturally adapted about breast feeding. Moreover baby friendly initiative had been taken and implemented in this hospital. The incidence had been found to be $2.9 \%$ in first 7 weeks postpartum in a western study by Kaufman $\mathrm{R}^{17}$ There were $4.5 \%$ cases of VVF following caesarean section due to obstructed 
labour.VVF was more common following obstructed labour a few years ago but recently it is becoming uncommon because of introduction of Partograph in many places and availability of EOC services all over the country. Caesarean sections are now done long before it is obstructed.There was only one cases that experienced obstetric palsy. In this case, she had history of a long trial at home and trial of instrumental delivery was failed. There was a case of postpartum blue in a primipara and had difficult labour, patient improved within a few days. One patient developed heart failure and was improved by packed cell transfusion and injection frusemide.

\section{Conclusion :}

Early puerperal infectious morbidity are common after a caesarean birth and risk factors includes low socioeconomic condition, PROM, prolonged labour or failed home trial, catheterization. So, early puerperal morbidities should not be neglected as this may interfere quality of life of a woman.

\section{References:}

1. Postpartum complications; journal of obstetrics and gynae, INDIA, 1994 vol,7; P-10.

2. Novy Md. Normal puerperium in Decherney AH, Nathan L, editors. Current obstetrics and Gynaecologic Diagnosis and treatment. 9th edition. McGraw Hill companies inc. 2003, 234-258.

3. Dutta Dc.Normal puerperium .Textbook of obstetrics. 5 th edition, New central book agency Ltd, 202;153164.

4. Howie PW. The puerperium in Edmonds DK. editor. Dewhurts textbook of obstetrics and gynaecology. 6th edition. Oxford Blackwell science Ltd.2001;342-353.

5. Alauddin M. Maternal mortality Bangladesh, Tangail, district,stud,fam planning 1986,17:3-21.

6. Pothinam S, Chanpoo T. Lumbiganon P. Post Caesarean section puerperal morbidity. The incidence and risk factors and risk factors at srinagarind Hospital. J Med Assoc Thai; 1992 Mar; 75(3), 173-7.

7. Rowshan A. Early postpartum period - A neglected tragedy (Dissertation), 2001;65-71.

8. Deeba F. A study of factors and outcome of emergency caesarean sections among the patients admitted in Rajshahi Medical College Hospital (Dissertation), 2001; 47-68.

9. Kwast BE, puerperal Sepsis: its contribution to maternal mortality. ICM/WHO/UNICEF-precongress workshop in kobe.Japan,october,1990, midwifery. 1991 sep;7(3):102-6.

10. Dare Fo, Bako, AU, Ezechioc, puerperal sepsis: a preventable postpartum complication, Department of obstetrics and Gynaecology, college of Health sciences, obafemi awolowo university, IU-IFe, Osun state, Nigeria, Trop Doct. 1998 Apr;28(2);92-5.

11. Rehu M, Nilsson CG. Risk factors for febrile morbidity associated with caesarean section. Obstet Gynecol 1980 Sep; 56(3):269-73.

12. Watts DH, Krohn MA, Hillier SL, Eschenbach DA. Bacterial vaginosis as a risk factor for post caesarean endometritis, Department of obstetrics and Gynaecology, university of washington, Seattle, obstet Gynaecol.1990 Jan; 75(1):52-8.

13. Gibbs RS. clinical risk factors for puerperal infection.Obstet Gynaecol 1980. May;55(5 suppl): 178-184.

14. Decherny AH, Nathan L, postpartum haemorrhage and the abnormal puerperium. Current obstetrics and Gynaecologic Diagnosis and treatment 9th edition, Mc Graw Hill companies Inc. 2003;531-552.

15. Emmons SI, Krohn M,jackson M, Eschen bach DA. Development of wound infections among women undergoing caesarean section. Department of obstetrics and Gynaecology, university of Washington, Seattle, obstet Gynaecol;1998 oct;72 (4), 559-64.

16. Gerber B, Schnidt H, Ohde A. Diagnosis of urinary tract infections in puerperium. UnivesitiesFravenklink, university Roskock. 1994 Sep; 54(9).

17. Kaufmann R, Foxman B. Mastitis among lactating women: occurrence and risk factors, Department of epidemiology, university of michigan school of public Health, Ann Arbor 48/V9-2029. Soc sci Med 1991;33(6):701-5. 